\title{
The Impact of Media Exposure on Intention to Purchase Green
}

\section{Electronic Products amongst Lecturers}

\author{
Iman Khalid A. Qader (Corresponding author) \\ School of Management, University Sains Malaysia \\ 11800 USM, Penang, Malaysia \\ Tel: 60-1-6-514-9319Ｅ-mail: iman@usm.my
}

Prof. Yuserrie Bin Zainuddin

Faculty of Manufacturing Engineering \& Technology Management

University Malaysia Pahang

26300 Gambang Kuantan, Pahang Darul Makmur, Malaysia

Tel: 60-1-9-416-4455Ｅ-mail: yuserrie@ump.edu.my

\begin{abstract}
The purpose of this study is to contribute to the body of knowledge in the area of green product purchase intention within the domain of green marketing, where all activities are designed to generate and to facilitate any exchanges intended to satisfy human needs or wants, such that the satisfaction of these needs or wants occurs, with minimal detrimental impact on the natural environment. Therefore, this study intends to identify the influence of media exposure, on purchase intention of lead-free electronic products (green electronics) amongst lecturers. Through a self-administered questionnaire among 170 lecturers, from USM main campus and USM engineering campus the study found some revealing insights. Through the results of this study, media exposure had a significant positive influence on lecturers' purchase intention. The theory of planned behavior Azjen (1985) supported the findings of this study for media exposure and purchase intention, which is related to the motivation part of the theory which includes information about a behavior, resulting in motivation to perform a certain behavior.
\end{abstract}

Keywords: Green marketing, Green electronic products, Lecturers, Media exposure, Purchase intention, Theory of planned behavior

\section{Introduction}

Green or environmental marketing is defined by Polonsky (1994) as all activities that are designed to generate and facilitate any exchanges intended to satisfy human needs or wants, such that the satisfaction of these needs and wants occurs, with minimal detrimental impact on the natural environment. Therefore, this study sheds some light on the problem of the pollution by revealing the dark side of high technology, polluted drinking water, waste discharges that harm fish and wildlife, high rates of miscarriages, birth defects, and cancer clusters in another word it has a direct impact on the environment and an indirect impact on the consumer via drinking water (Napp, 1995). The dark side of high technology is caused by the use of vast amounts of hazardous materials in the high-tech industry in fueling its global expansion of the rapidly changing product lines which is significantly depleting natural resources. Therefore, society is becoming more concerned with the natural environment and businesses have a begun to modify their behavior in an attempt to address society's new concerns Cannis (2001). According to Ottman (1993) it appears that all types of consumers both individual and industrial are becoming more concerned and aware about the natural environment.

Polls consistently show that a large majority of U. S. citizens have shown that saving the environment is a high priority to most American citizens, with public concern growing faster than any other issue (Schwartz \& Miller, 1991). In a 1992 study of 16 countries, more than $50 \%$ of consumers in each country indicated they were concerned about the environment. However, this study intends to identify a part of the problem of pollution, which is caused by the disposal of high-tech electronic products at the end of the products life cycle. In Malaysia, the electronic industry accounts for around $60 \%$ of the country's manufacturing exports and is the leading industrial sector in terms of investment, industrial output and employment. Major export products were electrical 
\& electronic products with a total value of US\$ 69.9 billion, representing 49.6\% of Malaysia's global export. In terms of products, Malaysia's main imports were electrical \& electronic amounted to US\$ 51 billion representing $44.5 \%$ of Malaysia's global import. Although Malaysia is a major exporter of electrical and electronic products, at the same time Malaysia imports electric and electronic products into the country. The typical electronic product may contain more than 1,000 different substances, some of which are potentially hazardous to the environment and to human health. Therefore, if old equipment is not properly recycled, these substances could seep into air, soil, and water, and have a direct polluting impact on the environment and an indirect polluting impact on humans caused by the accumulation of hazardous substances in lakes and rivers. (Malaysia's Global Trade accessed on-line http://www.koima.or.kr/jiran/korea/magazine, May.2006).

Hatija (2003) Research Officer Consumers Association of Penang, stated in PCBs symposium in Malaysia, "Given the many applications of PCBs (Polychlorinated biphenyl) in industries it is likely that products and equipment that contained PCBs would be disposed off as regular garbage. This is because there has not been much concern given to the disposal of hazardous household waste such as electrical equipment or products which are likely to contain PCBs in Malaysia". PCBs are made up of more than 200 related compounds these manufactured substances exhibits many ideal characteristics such as fire resistance, high stability. They also do not conduct electricity and have low volatility at normal temperature. These and other properties have made them desirable components in a wide range of industrial and consumer products. These same properties make the PCBs environmentally hazardous- especially their extreme resistance to chemical and biological breakdown by natural process in the environment. Due to their stability, PCBs have a high potential for bioaccumulation it is able to accumulate in aquatic environments such as lakes and rivers. As early as 1985 tests conducted on shellfish collected from sea bed around Penang island showed PCBs content to be in the range of $400-600 \mathrm{ppb}$. The amount of PCBs detected exceeded the permitted level set by the Food and Drug Authority (FDA) of 300 ppb. In 1992, tests conducted on 25 rivers in Peninsular Malaysia for PCBs residue showed that the amount was higher in the rivers that flow through industrial or densely populated area. The amount of PCBs detected was found to be in the range of 2.1 - 0.9 milligram per liter. This exceeds the level in the Proposed Interim National Quality Standards for Malaysia, which sets a standard of 0.044 milligram per liter of PCBs in effluents (Hatija, 2003).

Therefore, according to Said, Ahmadun, Paim and Masud, (2003) environmental problems are related directly or indirectly to the patterns of production by industries, consumption and behavior of the consumers. Hence, this study intends to explore the influence of media exposure on lecturers' purchase intention of electronic green products. Lecturers are considered relatively heavy users of electronic products; therefore, their intention to purchase green electronic products is the focus of the study. University lecturers will be chosen from five main perspectives; Firstly, from an economic perspective according to Noor and Ainin (2005), university lecturers have the purchasing power which means they can afford to purchase high-tech computers and electronics for personal use and in utilizing research grant budget to purchase electronic equipment. Secondly, from a social perspective university lecturers are considered heavy users of computers and electronic products Majid (1999), either for their personal use or for teaching, involvement in research grants and consultancy. Thirdly, from professional perspective university lecturers have the need for add-on peripherals such as a printer, modem, or storage system, which works in conjunction with a computer Sam, et al. (2005). Fourthly, from a political perspective university lecturers are aware of government rules and regulations which can influence their use of green electronics. Finally, while environmental issues are not well known by the general public, university lecturers are considered opinion leaders and the more opinion leaders are valued and respected, the more likely an innovation is to spread ( Perner, 2006).

\section{Literature Review}

\subsection{Behavioral Intention}

Behavioral intention has been defined by Azjen (2002) as human actions that are guided by three kinds of considerations; beliefs about the likely outcomes of the behavior and the evaluation of these outcomes( behavioral beliefs), beliefs about the normative expectations of others and motivation to comply with these expectations (normative beliefs), and beliefs about the presence of factors that may facilitate or impede performance of the behavior and the perceived power of these factors( control beliefs). As a general rule, the more favorable the attitude and subjective norm, and the greater the perceived control, the stronger should be the persons' intention to perform the behavior in question. As for consumers' purchase decision, Kotler and Armstrong (2001) argued that, in the evaluation stage, the consumer ranks brands and forms purchase intentions. Generally, the consumer's purchase decision will be to buy the most preferred brand. However, two factors can come between purchase intention and purchase decision the first factor is the attitude of others and the second factor is unexpected situational factors for example; the consumer may form a purchase intention based on 
factors such as expected income, expected price, and expected product benefits. In addition, Miller (2005) identifies behavioral intention as a function of both attitudes toward a behavior and subjective norms toward that behavior, which has been found to predict actual behavior. Hence, this study conceptualized purchase intention as a person's plan to engage in some action within a specified period of time and the probability that he or she will perform a behavior. Therefore, this study intends to investigate the influence of media exposure on lecturers purchase intention of lead-free electronic products.

\subsection{Media Exposure}

Most researchers agree that media have played a major role in the widespread dissemination of environmental concern (Lowe \& Rudig, 1987; Mitchell, 1990; Lowe \& Morrison, 1984). The amount and type of media coverage of environmental disasters and conflicts has helped transform many specific problems into a major public issue. Hence, Mazis and Raymond (1997) argued that advertisers use a variety of media to communicate product benefits to a target audience. For example, television commercials may be used for product demonstrations, print advertisements may be used to communicate information that is more detailed and to establish a brand image, and product packaging may be used to attract consumers at the point of sale (Belch \& Belch 1995). The uses of these media are often coordinated into a single integrated communications campaign However, Schultz and Lauterborul (1993) defined media exposure as any opportunity for a reader, viewer, or listener to see or hear an advertising message in a particular media vehicle. Media exposure is an important driver of the innovation diffusion and has a significant impact on innovators (Bass 1969). Media exposure's most powerful effect on diffusion is that it spreads knowledge of innovations to a large audience rapidly (Rogers 2003). According to DeFleur, Melvin, and Everett Dennis (1998), no one disputes the fact that media can help alter behavior and beliefs. What is important to keep in mind, however, is that most of those effects are small and, if truly effective, accumulative. In other words, tiny bits of information add up. Repetition of a message, its consistency over time, and apparent corroboration can help shift public opinion over the long-term. This process has helped change attitudes and behavior in a variety of contexts, some for the better, and some for the worse. Based on the foregoing literature, it can be argued that media exposure is an important predictor of purchase intention. Hence, on the following hypothesis was developed:

H1. Media exposure has a significant positive influence on the consumer's purchase intentions.

\section{Methodology}

\subsection{Sample}

The population for this study consists of full time university lecturers from University Sains Malaysia which has been considered the second oldest university and has emerged as the country's largest universities in terms of academic programs, student enrollment, and infrastructure. Respondents will be full time university lecturers from the university's main campus and from the university's engineering campus, based on academic staff statistics obtained from the University chancellery on January (2007) there are 898 full time university academic staff working on main and engineering campus. Therefore, by using the stratified proportionate sampling method a list of names of lecturers working in each school was obtained either from the university directory book or from USM website and once the population has been stratified into 25 major schools, $20 \%$ of the total number of academic staff working in each school will be drawn. Therefore, the target number of questionnaires need to be collected is 179 . However, 175 were returned, 4 questionnaires were not returned and 5 were rejected due to incompleteness and were unusable. Hence, 170 completed sets will be used for the data analysis in this study there by giving a total of $95 \%$.

University lecturers were chosen from five main perspectives; Firstly, from an economic perspective according to Noor and Ainin (2005), university lecturers have the purchasing power which means they can afford to purchase high-tech computers and electronics for personal use and in utilizing research grant budget to purchase electronic equipment. Secondly, from a social perspective university lecturers are considered heavy users of computers and electronic products Majid (1999), either for their personal use or for teaching, involvement in research grants and consultancy. Hence, according to Hoe (2006) all academics of Universiti Kuala Lumpur Institute InfoTech MARA (UniKL IIM) are required to use the e-learning portal in their teaching activities, it is compulsory for Lecturers, Assistant Lecturers and Instructors to use at least 60 percent of the features available in the portal and upload at least 50 percent of the lecture notes to the portal. The usage of the portal contributes 10 percent to individual achievement in the annual performance evaluation.

Thirdly, from professional perspective university lecturers have the need for add-on peripherals such as a printer, modem, or storage system, which works in conjunction with a computer Sam, et al. (2005). In addition, for example university lecturers in University Sains Malaysia are all given one desktop personal computer, apart 
from desktop PC given by the University; some lecturers have their own notebooks bought using their own pocket money or grants. However, since the life-cycle of electronic products is short, according to information obtained from the School of Computer and Communication, USM, (2007) computers given to lecturers will be changed when the technology is already backward as compared to current trend, hence, every 3 to 5 years; new computers are supplied to lecturers. Fourthly, from a political perspective university lecturers are aware of government rules and regulations which can influence their use of green electronics. Finally, while environmental issues are not well known by the general public, university lecturers are considered opinion leaders and the more opinion leaders are valued and respected, the more likely an innovation is to spread (Lars Perner, http://www.LarsPerner.com (accessed online 2006).

\subsection{Measurement of variables}

Independent variable- media exposure: In this study media exposure is conceptualized as the type and frequency of media coverage on environmental issues that help shape consumer's beliefs. Wray (2005) measured media exposure using 10 items using media type-exposure questions, and dose-exposure questions. Therefore, the measurements for this variable will be adapted from Wray (2005) using eight items. Individuals will be asked whether they have been exposed to any advertisements through television, radio, newspapers and billboards, if the answer is yes individuals would be then asked how many times they have been exposed to that type. For example; in the last 3 months, do you remember seeing any newspaper articles talking about environmental issues? If the answer is yes, then the individual will be asked how many times 1-5 times, 6-10 times 11-15, more than 15 times.

Dependent variable-Purchase intention: Azjen (2002) used three statements to measure intention" I intend to ..." "I will try to" and "I plan to...." However, the measurements for this variable will be adapted from Azjen (2002) there will be a slight change in the wording of the statements, so it will be better understood by the respondents who in turn, will have to give answers to 3 statements for this variable. The dichotomous scale will be used to measure purchase intention.

\section{Results and Findings}

A total of 200 sets of questionnaires were distributed to academic staff working in 25 major schools in University Sains Malaysia main campus and engineering campus. The drop and pick technique method was used in distributing and collecting the questionnaires. The total of full time university academic staff working on main and engineering campus is 898 . Therefore, by using the stratified proportionate sampling method a list of names of lecturers working in each school was obtained either from the university directory book or from USM website and once the population has been stratified into 25 major schools, $20 \%$ of the total number of academic staff working in each school was drawn. Two hundred questionnaires were distributed, target number of questionnaires (sample size) needed to be collected was 179, however, 175 were returned, 4 questionnaires were not returned and 5 were rejected due to incompleteness and were unusable. Hence 170 complete sets will be used for the data analysis in this study thereby giving a total response rate of $95 \%$. Based on Hair et al., (2006) a sample size of 100 is considered sufficient to carry out the analysis. (Table1 Appendix A) shows the response rate description and result.

\subsection{Profile of Respondents}

In terms of gender, $39.4 \%$ of respondents were females and $60.6 \%$ were male respondents, this indicates that the majority of respondents were male lecturers. In terms of age, $1.2 \%$ of respondents were below the age of 29 years old, while the majority of respondents $41.2 \%$ aged between 40 to 49 years old, followed by $38.2 \%$ of respondents were between the age of 30 to 39 years old, and the remaining $19.4 \%$ of respondents were above 50 years old. From ethnic back ground perspective, $72.4 \%$ of respondents were Malay, $11.2 \%$ were Chinese, $8.2 \%$ were Indians and $8.2 \%$ were other races. In terms of professional status, the majority $48.2 \%$ were lecturers, followed by $33.5 \%$ were associate professors, $17.1 \%$ were senior lectures and $1.2 \%$ were professors. Therefore, from the analysis it is apparent that the majority of respondents are in the lecturer category which are young and potentially holding more funds for research in future. In terms of years of experience, $31.8 \%$ of respondents had working experience lower than 5 years, $17.6 \%$ of respondents had working experience between 5 to 10 years, followed by $31.8 \%$ of respondents had working experience between 11 to 20 years, and $16.5 \%$ of respondents had working experience between 21 to 30 years. Lastly, $2.4 \%$ of respondents had working experience above 30 years. From this analysis, it appears that the majority of respondents had medium to high number of years of experience; this reflects that during respondents' years of experience on the job they will be liable to a number of research grants which will enable them to purchase electronic products for research purposes. This is supported by the following analysis on lecturers' number of research grants awarded to them during their years of 
experience. However, in terms of research grants, from the analysis it appears that $81 \%$ of respondents have a research grant ranging from 1 to 32 . This means that lecturers tendency to use computers and other electronics is high, this can be shown from the number of research grants awarded to them, which enables them to purchase electronics equipment and add on peripherals such as; printer, modem, storage system, which works in conjunction with a computer.

\subsection{Sample characteristics- Media Exposure}

Respondents' exposure levels by type of media ranged from $88.2 \%$ exposed to newspaper articles, while $87.1 \%$ of the respondents were exposed to local news stories and $58.8 \%$ of respondents were exposed to radio advertisements, finally $57.1 \%$ were exposed to billboards. Among respondents reporting exposure to different types of media, the median number for newspaper articles was 1-5 times, while the median number for local news stories was $1-5$, and the median number for radio advertisements was $1-5$, and finally the median number for billboards is one.

The results of the analysis indicate that respondents are exposed to some type of media coverage ranging from newspaper articles, news stories, and radio advertisements to billboards, therefore, the type and dose of exposure to different media coverage on environmental issues helps shape peoples believes. This finding is in line with Lowe and Rudig, (1987); Mitchell,(1990) and Lowe and Morrison, (1984) that the amount and type of media coverage of environmental disasters and conflicts has helped transform many specific problems into a major public issue. (Table 2 Appendix A) illustrates respondents' exposure levels and dose of exposure to different types of media. The descriptive statistics for this variable is shown in Table 3 (Appendix A).

\subsection{Sample Characteristics- Purchase Intention}

When measuring respondents purchase intention, three questions were asked to measure this construct, in the first question respondents were asked whether they intended to purchase a lead-free electronic product in future and $98.2 \%$ intended to purchase lead-free electronic products while $1.8 \%$ did not intend to purchase lead-free electronic products. Respondents were asked in the second question whether they would try to purchase a lead-free electronic product in future, and $98.2 \%$ replied yes and $1.8 \%$ no. Finally, in the third question respondents were asked whether they would plan to purchase a lead-free electronic product in future, and $98.2 \%$ replied yes and $1.8 \%$ replied no. The results indicate that the vast majority $98.2 \%$ of respondents and in this case lecturers expressed positive intentions to try and to plan to purchase an electronic green product in future, and in this case lead-free electronic products. The descriptive statistics for this variable is shown in Table 3 (Appendix A).

\subsection{Regression between media exposure and purchase intention}

Table 4 (Appendix A) illustrates the regression between media exposure and purchase intention. Hence, media exposure exhibited a significant influence on purchase intention, at $\beta=-.184, \mathrm{t}=2.428, \mathrm{p}<0.05$ However, media exposure explained 3 percent of the variation with purchase intention (i.e. $\mathrm{R}^{2}=0.034$ ). Hence, $\mathrm{H} 1$ is supported.

\section{Discussion}

Media exposure is conceptualized as the type and frequency of media coverage on environmental issues that help shape consumer's beliefs. In the current study, measurement for media exposure has been adapted from Wray (2005) in the measurement media exposure is measured by frequency and dose of exposure to various media types. Although, the findings of this study show that $88.2 \%$ of lecturers are all exposed newspaper articles, while $87.1 \%$ of lecturers are exposed to local news stories. In addition, $58.8 \%$ of lecturers are exposed to radio advertisements, and $57.1 \%$ have exposed to billboards. However, dose of exposure is considered rather low, among lecturers reporting exposure to different types of media, this can be shown from the findings that $11.2 \%$ of lecturers are not exposed to newspaper articles on environmental issues, and 52.9\% are exposed to newspapers articles on environmental issues, 1 to 5 times in a three-month period. However, it seems that $11.8 \%$ of lecturers have not seen local news stories on environmental issues, while $53.5 \%$ have seen local news stories on environmental issues 1 to 5 times in a three-month period. In addition, $40.6 \%$ of lecturers have not heard radio advertisements on environmental issues, while $37.1 \%$ hears a radio advertisement only 1 to 5 times in a three month period. Finally, $42.4 \%$ of lecturers do not remember seeing billboards, and $16.5 \%$ of lecturers do remember seeing a billboard on the environment 1 to 5 times in a period of three months. The findings indicate that although lecturers were exposed to the four types of media, but the level of exposure is low.

\section{Conclusion}

This study has shed some light on the problem of pollution, which is caused by the consumption of high-tech electronic products and the disposal of these products at the end of the products life cycle. Hence, this study 
investigates the influence of media exposure on purchase intention amongst lecturers because lecturers are considered relatively heavy users of electronic products. Due to their profession and technological consumption their intention to purchase lead-free electronic products (green electronics) is the focus of the study. However, through a survey among lecturers working full time in USM main campus and USM engineering campus the study found some revealing insights. In terms of theoretical contribution, the theory of planned behavior (TPB) Azjen (1985) supported the findings of this study for media exposure, and purchase intention which is related to the motivation part of the theory which includes information about a behavior, leads to motivation to perform a behavior. Therefore, from the results of the study media exposure had a significant influence on purchase intention. In terms of practical contribution of this study, it is recommended that marketers should constantly monitor and evaluate the needs and concerns of university lecturers by taking into account lecturer's exposure to the media. Hence increasing the dose of media will optimize consumer awareness towards environmental problems, and hence, influence positive attitudes, as media plays an important role in shaping consumers attitudes and their levels of participation in environmental actions and behaviours. Therefore, when catering for this segment of consumers the findings of the study should be taken into consideration.

\section{Acknowledgements}

The authors acknowledge the research grant provided by Universiti Sains Malaysia, Penang that has resulted in this article.

\section{References}

Axelrod, L. J. (1968). Reference in Donald G. Morrison. (1979). Purchase Intentions and Purchase Behavior. Journal of Marketing, vol.43, No.2. PP.65-74.

Azjen, I. (2002). Constructing a TPB Questionnaire: Conceptual and Methodological Considerations.

Azjen, I. (2002). Residual effects of past on later behavior: Habituation and reasoned action perspectives. Personality and Social Psychology Review, 6, 107-122.

Bass, Frank M. (1969). A New Product Growth Model for Consumer Durables. Management Science 15 (5):215-227.

Blanco, E. (2001). Presentation to the Board of the Deep South Center for Environmental Justice. Xavier University of Louisiana, New Orleans, Louisiana.

Blech, G.E., \& Blech, M.A. (1995). Advertising and Promotions: an Integrated Marketing Communications Perspective. New York.

Brombacher, J., \& U.Hamm. (1990). Ausgaben fur eine Ernahrung mit Lebensmitteln aus alternative Aunbau. Agra Europe, 7, 1-11.

Buttel, F.H. (1987). New directions in environmental sociology. Annual Review of Sociology, Vol.13, pp.465-488.

Cannis J. (2001). Green IC Packaging. Advanced Packaging, Vol.8, Pg. 33-38.

Cyrus H.Tahmassebi. (2003). Market forces versus regulation Chief Economist and Director of Market Research. Ashland Oil Inc, PO Box 391, Ashland, KY 4114, USA.

DeFleur, M, \& Everette Dennis. (1998). Understanding Mass Media, 6th Ed. Boston.

Fikry, A. Mohamed. (2000). First sub-regional training workshop on environment statistics ESCAP Malaysia Bangkok, Thailand.

Hair, J.F., Black, W.C., Babin, B. J., Anderson, R. E., \& Tatham, R.L. (2006). Multivariate Data Analysis. 6th Edition. Prentice Hall International, Inc.

Hatija, H. (2003) PCBs Situation in Malaysia. [Accessed May 2005] Available: http://tabemono.info/report/former/pcd/2003/malaysia/e_1.html

Hill, T., Smith, N.D., \& Mann, M. F. (1987) Role of efficacy expectations in predicting the decision to use advanced technologies. Journal of Applied psychology, 72, 307-314.

Hoe, W. T. (2006). In search of effectiveness factors: A case study of the unikl IIM e-learning portal master of multimedia (e-learning technologies) faculty of creative multimedia university.

Kotler, P., \& Armstrong, G. (2001). Principles of Marketing, 9th Edition, by Prentice Hall, Inc., Upper Saddle River, New Jersey. 
Langerbein,B., \& B. Wirthgen. (1987). Konsumverhalten der kaufervon alternativ erzeagen Nahrungsmitteln in Nordhessen. Brichete uber Landwirlschaft, 65-1-23.

Lowe, P., \& D. Morrison. (1984). Bad news or good news: Environmental politics and mass media. Sociological Review, Vol.32, pp.75-90.

Lowe, P.D., \& W. Rudig. (1987). Review article: Political ecology and the social science-The state of art. British Journal of Political Science, vol.16, pp.513-550.

Majid, S., Alfia Fanilievna Abazova. (1999). Computer literacy and use of electronic information sources by academics: A case study of International Islamic University Malaysia. Journal: Asian Libraries, Volume: 8 Issue: 4 Page: $100-111$.

Miller, K. (2005). Communications theories: perspectives, processes, and contexts. New York: McGraw-Hill.

Mitchell, R.C. (1990). "Public opinion and the green lobby: Poised for the 1990s?" In Environmental Policy in the 1990s: Toward a new agenda. N.J. Vig and M.E. Kraft (eds). Washington, D. C.: Congressional Quarterly Pr., pp.81-99.

Morrison, D. G. (1979). Purchase Intentions and Purchase Behavior. Journal of Marketing, Vol. 43, No. 2, 65-74.

Napp D. (9-12 October 1995). Lead-Free Interconnect Materials for the Electronic Industry, In: Proceeding of the 27th International SAMPE Technical Conference, Albuquerque, NM, pg 342.

Noor,I. J \& Ainin, S. (2005). Domestic Computer Usage and Activities in West Coast Malaysia: age and income differences. University of Malaya. Information Development, Vol. 21, No. 2, 128-137.

Olli, E., Grendstad, G., \& Wollebaek, D. (2001). Correlates of environmental behaviors: Bringing back social context. Environment and Behavior, 33(2), 181-208.

Ottman, Jacquelyn. (1993). Green Marketing: Challenges and Opportunities for the New Marketing Age. Lincolnwood, Illinois: NTC Business Books.

Polonsky, Michael Jay. (1994). Green Marketing Regulation in the US and Australia: The Australian Checklist. Greener Management International, 5: 44-53.

Said, A., Ahmadun, F., Paim, L., \& Masud, J. (2003). Environmental concerns, knowledge and practices gap among Malaysian teachers. International Journal of Sustainability in Higher Education, 4(4), 305-313.

Sam, H. K., Othman, A. E. A., \& Nordin, Z. S. (2005). Computer Self-Efficacy, Computer Anxiety, and Attitudes toward the Internet: A Study among Undergraduates in Unimas. Educational Technology \& Society, 8 (4), 205-219.

Schultz, P.W., \& Lauterborul, Z.C. (1993). Values and pro environmental behavior: A five -country survey. Journal of Cross- Cultural Psychology, 29 (4), 540-558.

Sewall. (1978). Reference in Donald G. Morrison. (1979). Purchase Intentions and Purchase Behavior. Journal of Marketing, vol.43, No.2. PP.65-74.

Silk and Urban. (1978). Reference in Donald G. Morrison. (1979). Purchase Intentions and Purchase Behavior. Journal of Marketing, vol.43, No.2. PP.65-74.

Smith. (1965). Reference in Donald G. Morrison. (1979). Purchase Intentions and Purchase Behavior. Journal of Marketing, vol.43, No.2. PP.65-74.

Uusitalo, L. (1990). Are environmental attitudes and behavior inconsistent: Findings from a finished study. Scandinavian Political Studies, Vol.13, No.2, pp.211-226.

Van Liere, K.D., \& R.E. Dunlap. (1981). Environment concerns: Does it make a difference how its measured? Environment and Behavior, 13 (6):651-676.

Von Alvensleben, R., and M. Altamann. (1986). Die Nachfrage nach alternativen Lebensmitteein. Agrarwirtschaft, 10, 289-295.

Wall, Glenda. (1995). Barriers to individual environmental action: The influence of attitudes and Social Experiences. Canadian Review of Sociology Anthropology, vol.32 Issue 4, pp 28-465.

Wray, R.J., Jupka, K., \& Ludiwg-Bell, C. (2005). A community -wide media campaign to promote walking in a Missouri town. [Accessed online Jan 2006] Available 


\section{Appendix A}

Table 1. Response Rate

\begin{tabular}{|l|c|}
\hline \multicolumn{1}{|c|}{ Description } & Result \\
\hline Questionnaires distributed & 200 \\
Target amont of & 179 \\
questionnaires & 175 \\
Questionnaires returned & 4 \\
Questionnaires un returned & 5 \\
Un usable Questionnaires & 170 \\
\hline \multicolumn{1}{|c|}{ Response rate } & $\mathbf{9 5 \%}$ \\
\hline
\end{tabular}

Table 2. Respondents levels of exposure and dose of exposure to types of media

\begin{tabular}{|c|c|}
\hline Type of Media & Percent \% \\
\hline $\begin{array}{l}\text { Respondents exposed to newspaper articles } \\
\text { Median number seen (1-5) } \\
\text { Respondents exposed to local news stories } \\
\text { Median number seen (1-5) } \\
\text { Respondents exposed to radio } \\
\text { advertisement } \\
\text { Median number seen (1-5) } \\
\text { Respondents exposed to Billboards } \\
\text { Median number seen (1) }\end{array}$ & $\begin{array}{l}88.2 \% \\
87.1 \% \\
58.8 \% \\
57.1 \%\end{array}$ \\
\hline Dose of Media Exposure & Percent\% \\
\hline $\begin{array}{l}\text { Newspaper articles } \\
0 \text { ( none) } \\
1 \text { ( low) } \\
2 \text { ( medium) } \\
3 \text { ( high) } \\
\text { Local news stories } \\
0 \text { ( none) } \\
1 \text { ( low) } \\
2 \text { ( medium) } \\
3 \text { ( high) } \\
\text { Radio advertisements } \\
0 \text { ( none) } \\
1 \text { ( low) } \\
2 \text { ( medium) } \\
3 \text { ( high) } \\
\text { Billboards } \\
0 \text { ( none) } \\
1 \text { ( low) } \\
2 \text { ( medium) } \\
3 \text { ( high) }\end{array}$ & $\begin{array}{r}11.2 \% \\
52.9 \% \\
21.8 \% \\
14.2 \% \\
11.8 \% \\
53.5 \% \\
24.7 \% \\
10.0 \% \\
40.6 \% \\
37.1 \% \\
13.5 \% \\
8.9 \% \\
42.4 \% \\
16.5 \% \\
17.1 \% \\
24.1 \%\end{array}$ \\
\hline
\end{tabular}

Table 3. Descriptive Statistics

\begin{tabular}{|l|c|c|c|c|}
\hline \multicolumn{1}{|c|}{ Type of variable } & Minimum & Maximum & Mean & $\begin{array}{c}\text { Std. } \\
\text { Deviation }\end{array}$ \\
\hline Media exposure & 1.00 & 2.00 & 1.7471 & 43598 \\
Purchase Intention & .00 & 1.00 & .0176 & .13205 \\
\hline
\end{tabular}


Table 4. Regression Analysis between Media Exposure and Purchase Intention

\begin{tabular}{|l|c|c|c|}
\hline Variables & Beta & t-values & Sig. \\
\hline Media Exposure & $.184^{* *}$ & 2.428 & .016 \\
\hline $\mathrm{R}^{2}=.034$ & $\mathrm{~F}=5.894 * *$ & Durbin-Watson Statistic $=2.133$ & \\
\hline
\end{tabular}

Note: $* * * \mathrm{p}<0.01$ and ${ }^{* *} \mathrm{p}<0.05$ and $* \mathrm{p}<.10$ 